\title{
Una provincia del Reino de Nápoles con fuerte concentración regalista: Tierra de Otranto y el entramado de la geografía de regio patronato entre los siglos XVI y XVII
}

\author{
Paola Nestola \\ Università del Salento \\ Dipartimento di Studi Storici dal Medioevo all'età Contemporanea* \\ paola.nestola@tin.it
}

Recibido: 11 de noviembre de 2009

Aceptado: 19 de mayo de 2010

\begin{abstract}
Resumen:
El artículo tiene como objetivo reconstruir el entramado de la geografía diocesana de patronazgo real en Tierra de Otranto entre los siglos dieciséis y diecisiete. Desde 1529 la corona española concentró en este teritorio sur-oriental del Reino de Nápoles el mayor número de circunscripciones de nombramiento real: sedes eclesiásticas localizadas en lugares de importancia estratégica desde el punto de vista político militar, diferentes en extensión, peso demográfico, consistencia patrimonial y prestigio simbólico. En esta emblemática área fronteriza, los hilos de la red de selección obispales eran flexibles y el entramado eclesiástico de regio patronato se cruzaba con las diócesis de elección pontificia y con los restantes poderes concurrentes y antagónicos. Por lo tanto, el objetivo es redefinir las configuraciones de las sedes en las que se ubicaron los obispos de probada fidelidad a la monarquía, en su mayor parte procedentes de la élite eclesiástica hispano - napolitana.
\end{abstract}

Palabras clave: Reino de Nápoles, Tierra de Otranto, provincia fronteriza, entramado diocesano, patronazgo real, obispos hispano-napolitanos, élites eclesiásticas.

\section{The 'Regalist Province': Tierra de Otranto (Naples) and the geographic network of regio patronato in sixteenth and seventeenth centuries}

\begin{abstract}
:
The main objective of this contribution is to reconstruct the diocesan geographic network of royal patronage in Tierra d'Otranto (Italy) in the sixteenth and seventeenth centuries. Since 1529 the Spanish crown concentrated the greatest number of royal ecclesiastical appointments in this southeastern territory of the Kingdom of Naples: dioceses were located in territories strategically important from a political
\end{abstract}

\footnotetext{
*Becaria Fundação para a Ciência e a Tecnologia (Portugal)
} 
and military point of view, territories which were nevertheless very different in demographic and geographical extension, as well as patrimonial power and prestige. In this characteristic borderland area, the mechanisms for selecting bishops were flexible and the ecclesiastic framework of regio patronato crossed with the pontifical dioceses and with other competing and antagonistic powers. Therefore, our aim is to redefine the organization of the seats in which the bishops, mostly from the Spanish-Neapolitan elite and of proven loyalty to the Spanish Monarchy, were placed.

Key words: Kingdom of Naples, Tierra de Otranto, borderland province, diocesan network, royal patronage, Spanish-Neapolitan bishops, ecclesiastical elites.

El pasado 29 de Junio se cumplió el 480 aniversario del Tratado de Barcelona firmado entre el papa Clemente VII y el emperador Carlos V. Un acontecimiento relevante tanto por la calidad de sus signatarios cuanto por las implicaciones que a nivel político, institucional y cultural tuvo en los heterogéneos espacios en los que se aplicó1. En el Reino de Nápoles el tratado tuvo importantes repercusiones en la organización de su geografía eclesiástica y en la consiguiente morfología de su episcopado. Aunque se percibiera por el mismo como una parcial victoria al no quedar todas sus nóminas bajo la tutela del patronato regio, se inició con él una nueva fase en la que veremos a algunos prelados doblemente legitimados en el ejercicio de sus funciones, al quedar estas sancionadas, de un lado, por la autoridad política y, del otro, por la canónica ${ }^{2}$. Una reducida élite eclesiástica con un variopinto cursus honorum a sus espaldas, abierta a la doble influencia hispano - napolitana. Asuntos todos ellos de suma importancia sobre los que la historiografía italiana se ha venido ocupando, en consonancia con el articulado cuadro de sus protagonistas en la estructura de la sociedad eclesiástica europea de la edad moderna. Marcos que también afectaron a los coetáneos sistemas políticos y a las respectivas costumbres sociales ${ }^{3}$.

${ }^{1}$ GALASSO, G.: Il Regno di Napoli: il Mezzogiorno spagnolo (1494-1622), Torino, Utet, 2005, vol. 15, pp. 681- 682; DE MARTINIS, R.: Le ventiquattro chiese del trattato di Barcellona fra Clemente VII e Carlo V, Napoli, Tipografia Editrice degli Accattoncelli, 1882.

${ }^{2}$ ROSA, M.: Diocesi e vescovi nel Mezzogiorno durante il viceregno spagnolo. Capitanata, Terra di Bari e Terra d'Otranto dal 1545 al 1714, en MUSCA, G. (ed.): Studi Storici in onore di Gabriele Pepe, Bari, Dedalo Libri, 1969, por Tierra de Otranto en particular pp. 561-574; vease además PROSPERI, A.: La figura del vescovo fra Quattro e Cinquecento: persistenze, disagi e novità, en CHITTOLINI G. y MICCOLI G. (eds.): La Chiesa e il potere politico dal Medioevo all'età Contemporanea, en: Storia d'Italia, Annali, vol. IX, Torino, Einaudi, 1986, pp. 217-262; FRAGNITO, G.: «Vescovi e cardinali fra Chiesa e potere politico», Società e Storia , 41,(1988), pp. 641-653; TORRE, A.: «Il vescovo di Antico Regime: un approccio configurazionale», Critica Storica, 31, 91, (1996), pp. 199-216.

${ }^{3}$ ROSA, M.:Clero cattolico e società europea nell'età moderna, Roma y Bari, Laterza, 2006; PROSPERI, A.: Vescovi e inquisitori per una società cristiana, en IDEM, Tribunali della coscienza. Inquisitori, confessori, missionari, Torino, Einaudi, 1996, pp. 278-289; por una comparación historiográfica de las relaciones inquisidores-obispos en las distintas áreas mediterráneas veáse la bibliografía indicada: BRAMBILLA, E.: La giustizia intollerante. Inquisizione e tribunali confessionali in Europa (secc. IV-XVIII), Roma, Carocci, 2006, pp. 89-104. 
Retomando algunos estudios sobre la incidencia del regio patronato en el Sur del territorio italiano, las páginas que siguen se centran en la red diocesana de una provincia de frontera como fue Tierra de Otranto ${ }^{4}$. Seguiremos por tanto una línea de investigación ya iniciada y que deseamos retomar valiéndonos de una labor de archivo realizada sobre todo en instituciones españolas de la que haremos mención a lo largo de este artículo ${ }^{5}$. Perfilaremos no tanto un dibujo exhaustivo de la situación cuanto un boceto ajustado, centrado en los años que corren entre la firma del acuerdo y la primera mitad del siglo XVII. Basado en precisas articulaciones eclesiásticas provinciales con fuerte arraigo regalista ${ }^{6}$, el plano se configura urdido en el interior de jurisdicciones antagónicas y entre el hacer y deshacer de poderes en pugna, en escenarios de perfiles inciertos, gobernados por autoridades periféricas cuya legitimación procede de soberanías en pugna o aliadas en función del cuándo y dónde, que a veces podían tener objetivos comunes pero que no siempre coincidían. Las complejas tramas jurisdiccionales, los territorios caracterizados por su dislocación y discontinuidad, así como autoridades con muy distinto grado de legitimidad y de diferente origen social y geográfico constituyen el dibujo de un intrincado sistema de hilos que han permanecido ocultos en la investigación. Sobre estos aspectos es necesario insistir para comprender en profundidad este territorio de la monarquía y a los individuos que en él actuaban.

\section{Campos de investigación: entre nudos historiográficos aflojados e hilos retomados}

Con los capítulos de paz estipulados en 1529 daba comienzo en el Reino de Nápoles una nueva y específica configuración de la malla diocesana y de su respectivo episcopado ${ }^{7}$. El día de la solemne festividad de los santos Pedro y Pablo - la misma que había tenido y tendría en el futuro rasgos rituales cada vez más cargados de significado político en las relaciones entre Roma y la corona española ${ }^{8}$ - se concedía a los soberanos de la casa de Habsburgo y a sus sucesores el derecho de presentación de los obispos de algunas circunscripciones eclesiásticas del amplio y fragmentado territorio del virreinato. Bajo la fórmula del derecho se aseguraba a Carlos de Habsburgo el control del personal que recibiría la mitra en 24 iglesias, entre diócesis y archidiócesis, agrupadas bajo el nombre de regio patronato, así como el control del

${ }^{4}$ VISCEGLIA, M.A.: Territorio, feudo, potere locale, Terra d'Otranto tra medioevo ed età moderna, Napoli, Guida, 1988; EADEM: Terra d'Otranto, dagli Angioini all'Unità, en GALASSO, G. y ROMEO, R. (eds.): Storia del Mezzogiorno, vol.VII, Le Province, Napoli, Edizioni del Sole, 1991, pp. 333-468.

${ }^{5}$ La investigación ha sido llevada a cabo en: Archivo Histórico Nacional de Madrid (AHNM); Archivo General de Simancas (AGS) y Archivio di Stato di Napoli (ASN).

${ }^{6}$ GRIBAUDI, M.: Scala, pertinenza, configurazione, en REVEL, J. (ed.): Giochi di scala. La microstoria alla prova dell'esperienza, Roma, Viella, 2006, pp. 113-143.

${ }^{7}$ DE MARTINIS,R.: Del Regio Patronato nelle provincie meridionali, Napoli,Tipografia Editrice degli Accattoncelli, 1877; IDEM, op.cit. (nota 1).

${ }^{8}$ Sobre esta ceremonia: VISCEGLIA, M.A.: La città rituale, Roma e le sue cerimonie in età moderna, Roma, Viella, 2002, pp. 212-213. 
personal de otras instituciones eclesiásticas menores ${ }^{9}$. Con respecto a las 131 sedes en que se articulaba la geografía eclesiástica del Reino de Nápoles, el 20\% de las circunscripciones que se concedían al monarca y a sus sucesores constituía un espacio parcial y limitado ${ }^{10}$, fuertemente sujeto a la influencia de la autoridad española, que en 1554, con el privilegio de la alternativa, redefiniría el reparto de diócesis entre aquellas «sin alternativa», «in alternativa», «in y sin alternativa» ${ }^{11}$. En la intricada red de sedes metropolitanas, archidiócesis y diócesis de época normando - aragonesa se fijaban por tanto los criterios para la elección de sus candidatos que podían ser: sólo extranjeros o, alternativamente, nacidos en la península ibérica y «naturales del Reyno».

Al acuerdo del '29 y a su evolución, así como a los procesos de selección de los candidatos, hay referencias tanto directas como indirectas en muchos y heterogéneos trabajos de la reciente historiografía italiana y extranjera ${ }^{12}$. Una parte de estos estudios, diferentes en enfoque y objetivos, se ha aproximado al tema partiendo de los estudios llevados a cabo a finales del siglo XIX por el Padre de la Misión Rafael de Martinis ${ }^{13}$. El lazarista napolitano dedicó no pocas energías al tema del tratado y del instituto inaugurado en 1529. Por ejemplo, en su primer estudio, utilizando diversas fuentes archivísticas y bibliográficas, subrayaba la falta de conformidad entre importantes documentos relacionados con los capítulos de paz firmados en Barcelona, haciendo notar la discordancia entre las diócesis de patronato regio recogidas en el acuerdo. $\mathrm{Si}$ bien todavía hoy día no parece resuelto el asunto, el estudio citaba la repartición en 7 archidiócesis y 17 diócesis de patronato regio partiendo de la distribución referida por

${ }^{9}$ DE MARTINIS R., op. cit. (nota 7, 1877), pp. 37-35; CONIGLIO, G.: «I benefici ecclesiastici di presentazione regia nel Regno di Napoli nel secolo XVI», Rivista di Storia della Chiesa in Italia, 5 , (1951), pp. 269-274.

${ }^{10}$ PALESE, S.: La Chiesa del Mezzogiorno nel Cinquecento pretridentino, en CESTARO, A. (ed.): Geronimo Seripando e la chiesa del suo tempo nel V centenario della nascita, Roma, Edizioni di Storia e Letteratura, 1997, pp. 83-103.

${ }^{11}$ SPEDICATO, M.: Il giuspatronato nelle chiese meridionali del Cinquecento. Diocesi e vescovi di presentazione regia prima e dopo il concilio di Trento, Ibidem, pp. 119-160; IDEM: Il mercato della mitra. Episcopato regio e privilegio dell'alternativa nel Regno di Napoli in età spagnola (1529-1714), Bari, Cacucci, 1996, p. 13; IDEM, Il trattato di Barcellona del 1529 e l'esercizio del patronato regio nel Viceregno di Napoli nell'età di Carlo V, en ANATRA, B. y MANCONI, F.: Sardegna, Spagna e Stati italiani nell'età di Carlo V, Roma, Carocci, 2001, pp. 381-389; IDEM, Il patronato regio nel Regno di Napoli in età moderna tra rivendicazioni giurisdizionali e processi amministrativi, en IDEM: Stati e chiese nazionali di antico regime, Galatina, EdiPan, 2006, pp. 75-121.

12 Junto a las referencias anteriores veáse: ROSA, M.: La chiesa meridionale nell'età della Controriforma, en CHITTOLINI y MICCOLI, op. cit. (nota 2), pp. 293-345, p. 298; BRANCACCIO, G.: Il trono, la fede e l'altare. Istituzioni ecclesiastiche e vita religiosa nel Mezzogiorno moderno, Napoli, Edizioni Scientifiche Italiane, 1996, pp. 225-256; BORROMEO, A.: Felipe II y la tradiciòn regalista de la Corona española, en MARTINEZ MILLÁN, J.: Felipe II (1527-1598): Europa y la Monarquia Catòlica, 4 voll., Madrid, Parteluz, 1998, vol. III, pp. 111-37; IDEM, Filippo II e il papato, en LOTTI, L. y VILLARI, R. (eds.): Filippo II e il Mediterraneo, Convegno internazionale di studi, Barcellona, 23-27 novembre 1998, Roma 2-4 dicembre 1998, Roma y Bari, Laterza, 2003, pp. 477-535, pp. 478 y 485.

${ }^{13}$ Sobre el vicenciano Raffaele De Martinis (1829-1900): GUERRA, G. c.m. y GUERRA, M.: Storia dei vincenziani nell'Italia Meridionale. Dall'arrivo a Napoli (1668) al Concilio Ecumenico Vaticano II (1962), Roma, Edizioni Vincenziane, 2003, p. 106. Sobre la presencia y la actividad de este orden: ROMANO, A.S.: «La Società di S. Vincenzo de’ Paoli a Napoli. Origini e primi sviluppi (18701877)», Campania Sacra, 39, (2009), pp. 129-174. 
Pietro Giannone: sólo una circunscripción entraba en las provincias de Principado Ultra, Molise y Calabria Citra; dos en Principado Citra, Abruzo y Basilicata; tres en Tierra de Lavoro, Calabria Ultra y Tierra de Bari; nada menos que siete en Tierra de Otranto $^{14}$.

Basándose en documentos de procedencia romana y española y retomando algunos aspectos jurídicos puestos en evidencia igualmente por de Martinis en Le ventiquattro chiese del trattato di Barcellon a fra Clemente VII e Carlo V, el trabajo de Mario Spedicato de $1996^{15}$ insistía en el patronato de jure en cuanto a las temporales prerrogativas de un acto libre y revocable, y ponía en evidencia los esfuerzos de Pío V por reducir tales derechos, afirmados definitivamente por Sixto V en 1589. Además, subrayaba el carácter improvisado y arbitrario de los mecanismos de asignación de cargos episcopales llevados a cabo a partir de mediados del siglo XVI en función de la "alternativa", haciendo resaltar la aplicación de la importante puesta en práctica para recuperar los sectores más influyentes de la aristocracia napolitana a la causa de la monarquía, que premiaba de esta manera a los súbditos más fieles a la corona. En relación con la plena victoria conseguida en otras áreas de la monarquía, la parcial y circunscrita concesión del ' 29 otorgada al soberano es vista, en este estudio, como una cuidada selección de las sedes, concentrada en puntos estratégicos y geográficamente importantes relacionados con coetáneos proyectos de defensa con los que hacer frente a la eminencia del peligro turco ${ }^{16}$. Por tanto, reordenación de la red eclesiástica regia y puesta en funcionamiento del sistema defensivo costero configuraban un plan que hacia coincidir las sedes episcopales más importantes con las ciudades con relevantes presidios militares. Resulta ejemplar la elección de las diócesis de Salerno, Gaeta y Bríndisi, una equilibrada selección de sedes portuarias acentuada en los dos últimos casos por su inclusión entre las sedes "sin alternativa", ancladas por tanto en la obligación de elegir sus obispos entre los candidatos de origen extranjero y no del reino.

El análisis de Spedicato ha proporcionado elementos útiles para conocer a medio y largo plazo la exacta aplicación del principio de alternativa, ilustrando algunos de los mecanismos y de las etapas del proceso de selección que conducían a la elección del heterogéneo cuerpo episcopal, designado, trasladado o enviado a las sedes diocesanas. Una trama de obligada referencia que en muchos casos ha proporcionado datos precisos con los que interpretar la concreta acción episcopal de alguno de sus miembros ${ }^{17}$. Se trata, además, de un marco que amplía el cuadro estadístico propuesto por Mario Rosa en su imprescindible estudio de 1969, una disección en clave comparativa de las tres provincias de Apulia (Capitanata, Tierra de Bari y Tierra

\footnotetext{
${ }^{14}$ DE MARTINIS, op. cit. (nota 7), pp. 18-19.

${ }^{15}$ SPEDICATO, op. cit. (nota 11).

${ }^{16}$ Ibidem.

${ }^{17}$ Aunque según distintos objetivos de investigaciones veáse: BORROMEO, A.: I vescovi italiani e l'applicazione del concilio di Trento, en MOZZARELLI, C. y ZARDIN, D.: I tempi del Concilio. Religione, cultura e società nell'Europa tridentina, Roma, Bulzoni,1997, pp. 27-105, p. 82, nota 36; CASSESE, M.: Girolamo Seripando e i vescovi meridionali (1535-1563), voll. II, Napoli, Editoriale Scientifica, 2002, vol. I, pp. 39-55; SPEDICATO, M.: Episcopato e processi di tridentinizzazione nella Puglia del sec. XVII, Galatina, Congedo, 1990.
} 
de Otranto) que proporcionaba una serie de claves para entender mejor la Historia del Sur de Italia durante el virreinato españo ${ }^{18}$. Elemento de fuerza de aquel estudio era la elocuencia numérica de las series de datos estadísticos, tanto económicos como de la morfología de su articulado episcopado. Un análisis que no olvidaba señalar que las diócesis de patronato se inscribían en áreas periféricas poco apetecibles, sedes en las que difícilmente se conseguía personal extranjero que quisiera trasladarse, dado lo exiguo de sus rentas.

Por su parte, enfocado de diferente manera y haciendo uso de una documentación de distinta naturaleza y procedencia, Vito Gallotta, en $1977^{19}$, insistía en la peculiar coincidencia derivada de la firma del tratado de Barcelona, destacando la convergencia jurisdiccional entre sedes de patronato y ciudades regias, entre el control real de la ciudad y de su obispo en las sedes metropolitanas y el derecho de nómina papal en las diócesis menores. Por otro lado, resulta imposible pensar que se dieran relaciones sin contrastes entre el obispo de presentación estatal y los oficiales de las ciudades de realengo. Unidos por la lealtad hacia el rey, los comportamientos eran diferentes para las autoridades periféricas al frente de instituciones que pertenecían a órdenes diversas, tales como el civil o el eclesiástico, cada uno con privilegios distintos que tutelar y hacer respetar. Estos antagonismos de carácter simbólico - práctico se agudizaban cuando el sujeto recibía la autoridad espiritual de fuentes tan diversas como la papal o la real y se activaban en una sociedad en la que el prestigio de las personas se vinculaba con la capacidad de deshilarse entre privilegios y jurisdicciones.

Tierra de Otranto era la provincia donde más alta era la concentración de diócesis regias y más evidente resultaba la peculiar configuración que hacía casi coincidir circunscripciones sujetas a la nómina real en la esfera eclesiástica y simultáneamente en la esfera civil. Ejemplares son los casos de las demarcaciones de Matera, Bríndisi, Taranto, Otranto y Gallipoli.

Estas interferencias jurisdiccionales son todavia inexplorados terrenos de investigación que tampoco han afectado estudios más recientes, que han puesto de manifiesto cómo los obispos eran dispuestos a transferirse a sedes poco apetecibles y escasamente remuneradas con tal de defender otros intereses privados, tutelando además los intereses de las familias de las que eran prestigiosos representantes ${ }^{20}$.

Llevadas a cabo hace más de veinte años, las distintas investigaciones han dejado sin esclarecer muchos aspectos que merecen un nuevo enfoque para dar relieve a un tema multiforme, siempre más encuadrado según planes de historia político-religiosa que no descuidan el ámbito económico y el análisis de los recursos materiales y sus repercusiones en las dinámicas sociales de los territorios de las monarquía ibérica durante los siglos XVI y XVII ${ }^{21}$.

\footnotetext{
${ }^{18}$ ROSA, op. cit. (nota 2).

${ }^{19}$ GALLOTTA, V.: «L'attuazione del Concilio di Trento nelle diocesi pugliesi», Annali della Facoltà di Magistero, 34, (1974-75; 1975-76), pp. 154-196 y pp. 181-182.

${ }^{20}$ METZLER, G.: «Clienti del papa, ministri del re. Le relazioni tra il cardinal nipote e ufficiali napoletani nel primo Seicento», Dimensioni e problemi della ricerca storica, 1, (2004), pp. 83-124.

${ }^{21}$ FERNÁNDEZ TERRICABRAS, I.: Por una geografía del patronazgo real: teólogos y juristas en las presentaciones episcopales de Felipe II, en MARTINEZ RUIZ. E. y otros (eds.): Iglesia y socie-
} 
Guiados por tan diversas perspectivas hemos intentado aplicar estos cuadros interpretativos al caso específico de Lecce, ciudad de realengo y además sede eclesiástica pontificia ${ }^{22}$. De ellos emerge cómo el centro vital de la geografía de la Tierra de Otranto estuvo sujeto simultáneamente, durante un preciso período, a la autoridad española en ámbitos tanto civiles como religiosos. Un caso anómalo, a tenor de cuanto preveían los planes historiográficos territoriales, que indicaban una tal coincidencia estatal y eclesiástica sólo en otros centros de la provincia. En Lecce, a mediados del siglo XVI, en el quicio de la "metamorfosis de un imperio", retomando la expresión de Mía Rodríguez Salgado ${ }^{23}$, a partir del episcopado de Braccio Martelli (1552 - 1560) se estableció una importante cesura en el mecanismo de selección de los obispos. Un cambio significativo en la elección de las autoridades eclesiásticas de la ciudad, llevado a cabo no ya según criterios estrictamente relacionados con el mantenimiento del equilibrio al interno del colegio de canónigos capitulares lecceses sino mediante formas de reclutamiento episcopal puestas en práctica de manera cada vez más eficaz entre la corona española y la curia romana.

La autoridad episcopal de la periférica capital de provincia era un prelado de origen florentino que pertenecía a una de las familias más importantes aliada con los Medici. En la primera mitad del siglo XVI un miembro de la familia de los Martelli ya había sido asignado a la circunscripción de Lecce. Al nuevo obispo, sin embargo, otras cualidades lo distinguían de su predecesor. A través de sus méritos personales se había distinguido en el ámbito curial, y por sus cualidades personales y por su ramificada red familiar había sido nominado para ocupar el obispado de Fiésole (1530-1552). Con este cargo «el obispo de Fesuli» ${ }^{24}$ fue el único representante de las sedes de la Toscana que participó en las primeras sesiones del Concilio en Trento y Bolonia. En aquellas agitadas sesiones se distinguió en particular por la defensa de los privilegios de los obispos frente a los ataques de los miembros de las órdenes regulares. Además, formó cuerpo con la idea de los representantes imperiales de no transferir el debate a Bolonia ${ }^{25}$. El nombramiento a la sede leccese fue el premio a su lealtad, ocasión que aprovecharía el titular de una densa circunscripción que había dado señales evidentes de fermentos heréticos ${ }^{26}$ en un preeminente centro de una simbólica región bajo la presión constante de un ataque turco. Fue también una

dad en el Antiguo Régimen, (s.1.), Asociación Española de Historia Moderna, 1994, vol. I, pp. 601-610; BARRIO GOZALO, M.: El real patronato y los obispos españoles del Antiguo Régimen (1556-1834), Madrid, Centro de Estudios Políticos y Constitucionales, 2004; PAIVA, J.P.: Os bispos de Portugal e do Império (1495-1777), Coimbra, Imprensa da Universidade de Coimbra, 2006.

${ }^{22}$ NESTOLA, P.: I grifoni della fede. Vescovi-inquisitori in Terra d'Otranto tra '500 e '600, Spedicato M., Paiva J.P. Prefacio, Galatina, Congedo, 2008, pp. 129-247.

${ }^{23}$ Nos referimos al estudio de RODRÍGUEZ-SALGADO, M. The Changing Face of Empire. Charles V, Philip II and Habsburg Authority (1551-1559), Cambridge, Cambridge University Press, 1988, traducido al italiano: Metamorfosi di un impero. La politica asburgica da Carlo V a Filippo II (1551-1559), Milano, Vita e Pensiero, 1994.

${ }^{24}$ AGS, Estado, leg. 1465, c. 59, carta de Francisco de Toledo a Carlos V de 15 de abril 1547; ivi, c. 42, carta de 22 mayo de 1547.

${ }^{25}$ ROGGER, I.: Le Nazioni al concilio di Trento durante la sua epoca imperiale (1545-1552), Roma, Herder, 1952, pp. 156 y 162 y 184; NESTOLA, op. cit. (nota 22), pp. 129-143 y relativa bibliografía.

${ }^{26}$ ASN, Collaterale Curiae, vol. 12, f. 162. 
inesperada ocasión para el ambicioso prelado, que deseaba escalar el cursus honorum de la jerarquía eclesiástica, según especificó el historiador Scipione Ammirato en su obra ${ }^{27}$.

De este modo, los anfibios mecanismos de selección para la mitra involucraban a la ciudad de Lecce, catapultándola hacia aquellos procesos que a mediados del siglo XVI adquirirán su peculiar fisonomía en Tierra de Otranto y en todo el Reino de Nápoles. En abril de 1553, el ingreso triunfal de Martelli a través del limes urbano representado por la "Puerta real" para la ceremonia de posesión ${ }^{28}$ supuso la primera entrada de un candidato seleccionado de acuerdo a los nuevos criterios. Tal pública liturgia de poder en el principal centro político regional constituía una especie de ritual de pasaje, ratificado a distancia por el soberano, quien gozaba además del derecho de nómina en las vecinas sedes de Bríndisi, Otranto y Gallipoli, amén de otras diócesis de la articulada y fragmentada geografía eclesiástica provincial.

Fortalecido con las concesiones recibidas y confirmadas por el emperador, la urbe se configuraba como el epicentro de una provincia con fuertes connotaciones regalistas. Con una reconocida primacía civil, la ambiciosa ciudad de realengo acusaba una cierta frustración en el ámbito eclesiástico derivada de su condición de sede episcopal sujeta a la metropolitana Otranto. Una situación que podría equilibrarse con la ayuda del soberano, quien podría modificar el tejido territorial convirtiéndola en archidiócesis. Por este motivo, haciendo referencia al articulado y complejo sistema de legitimación de la autoridad estatal, el baricentro político administrativo intentaba ostentar, distinguir y afirmar la propia supremacía sobre las jerarquías territoriales, a la vez que estrechar los lazos con la dinastía reinante. Apoyándose en la relación de protección tejida entre el emperador y el florentino Martelli, las oligarquías de la ciudad veían acercarse el momento propicio para modificar la geografía eclesiástica regional y alcanzar un nuevo equilibrio territorial. El historiador y polígrafo leccese Iacopo Antonio Ferrari, brazo ejecutivo de las ambiciones de la ciudad y de las veleidades del docto obispo florentino, fue quien mejor expresó el deseo de modificar estos equilibrios, amparándose en sus valores permanentes y describiendo las manifestaciones de fidelidad y lealtad de las que había dado muestras la ciudad. Con ellas, el soberano restituiría los títulos perdidos hasta «cancelar a la provincia salentina el vituperado nombre de Tierra de Otranto, y hacerla nombrar por el suyo [Lecce], convirtiendo el Obispo en Arzobispo» ${ }^{29}$.

\footnotetext{
${ }^{27}$ NESTOLA, op. cit. (nota 22), p. 142.

${ }^{28}$ Sobre estas específicas ceremonias: PAIVA, J.P. (ed): Religious Ceremonials and Images: Power and Social Meaning (1400-1750), Coimbra, Palimage Editores, 2002; por el contexto italiano RANDO, D.: Ceremonial Episcopal Entrances in Fifteenth Century North-Central Italy: Images, Symbols, Allegories, Ibidem, pp. 27-46; PAIVA, J.P.: A liturgy of power: solemn episcopal entrances in early modern Europe, en SCHILLING, H. y TOTH, I.G.(eds.): Cultural Exchange in Early Modern Europe, vol. I, Religion and Cultural Exchange in Europe, 1400-1700, Cambridge, Cambridge University Press, 2006, pp. 138-161. Para el específico caso de Lecce me permito indicar: NESTOLA, P.: Giochi di scala provinciale e liturgie di potere nella «fedelissima» Lecce del 'secolo di ferro', en «Mediterranea. Ricerche Storiche», 6, 17, (2009), pp. 517-542, además en: www.storiamediterranea.it

${ }^{29}$ Tradución del texto italiano por la que suscribe; veáse además NESTOLA, P.: «Oltre il limite identità e distinzione socio-territoriale a Lecce a metà '500», L'Idomeneo. Rivista della Società di Storia Patria per la Puglia sez. di Lecce, 10, (2008), pp. 119-129.
} 
En el curso de la edad moderna Lecce no consiguió nunca el deseado reconocimiento en la jerarquía eclesiástica provincial. Sin embargo, como veremos más adelante, a mediados del siglo XVII alcanzó una prominente posición en el plano simbólico - cultural, gracias a la acción de otro prelado, que inicio una lúcida estrategia de propaganda de cara a la provincia.

Este es el campo en el que seguimos investigando, focalizando la atención en aspectos de carácter simbólico - ritual tal y como a su vez ocurría en las restantes sedes del virreinato en las que recaía el derecho de presentación regia ${ }^{30}$.

\section{Equilibrios territoriales y selecciones obispales: nuevos enfoques}

En el caso específico de la provincia de Tierra de Otranto se trataba de una emblemática zona de frontera, en primera fila de los ataques turcos. Como se puede observar en el mapa realizado, de las catorce diócesis en que se dividía el territorio entre el 1591 y 1663, ocho (Matera, Taranto, Otranto, Bríndisi, Mottola, Oria, Gallipoli y Ugento) fueron las de patronato real guiadas por prelados seleccionados directamente por el soberano, quien para mayor garantía nombrò personal de origen hispano-napolitano ${ }^{31}$. Un corpus heterogéneo por origen geográfico y nacimiento, por experiencia y encargos, que venía premiado con este prestigioso y tangible ascenso social.

A la exigencia de control del territorio y del orden público de la monarquía católica, se juntò la de la iglesia romana interesada en reequilibrar la fuerte presencia del poder estatal $\mathrm{y}$, al tiempo, decidida a no perder jurisdicción, con intención de uniformar y orientar las prácticas sociales y los cultos, de disciplinar a las poblaciones locales que convivían con las restantes etnias exógenas presentes en el territorio de la provincia. Efectivamente bajo su nombramiento quedaban las diócesis de Castellaneta, Ostuni, Lecce, Castro y Alessano. Nardò, por su parte, estaba directamente sujeta a la Santa Sede.

De las cuatro circunscripciones arzobispales de patronazgo real de Tierra de Otranto, Taranto era la situada más al oeste de la provincia más lejana de Apulia. A raíz del tratado de Barcelona, la circunscripción jónica entró a formar parte junto a Otranto, Bríndisi y Matera. Esta última tenía sufragáneas en otra província y en 1656 se separó de Tierra de Otranto para recaer en la província administrativa de Basilicata $^{32}$. Los Habsburgo disfrutaban además del derecho de presentación sobre otras instituciones eclesiásticas, como la ciudad puerto de Gallipoli, sede diocesana

${ }^{30}$ LABANCA, A.: Giurisdizione regia e commerci nel Molise nella prima età moderna, en SPEDICATO, op. cit. (nota 13, 2006), pp. 266-284; SABATINI, G.: Le sentinelle della corona. I presidi militari spagnoli ai confini settentrionali del regno di Napoli nel Cinquecento, en RIZZO, M. y MAZZOCCHI, G.: La espada y la pluma. Il mondo militare nella Lombardia spagnola cinquecentesca, Baroni, Lucca, 2000, pp. 247-279; IDEM: El espacio italiano de la monarquía: distintos caminos hacia una sola integración, en prensa en Atti del Congresso internazionale "Las Indias Occidentales: procesos de integración en las Monarquías Ibéricas - III Jornadas de Historia de las Monarquías Ibéricas" (México, El Colegio de México, 25-27 settembre 2007).

${ }^{31}$ ROSA, M.: op. cit. (nota 2).

${ }^{32}$ PELLEGRINO, B.: Istituzioni ecclesiastiche nel Mezzogiorno moderno, Herder editrice e libreria, Roma, 1993, pp. 3-36. 


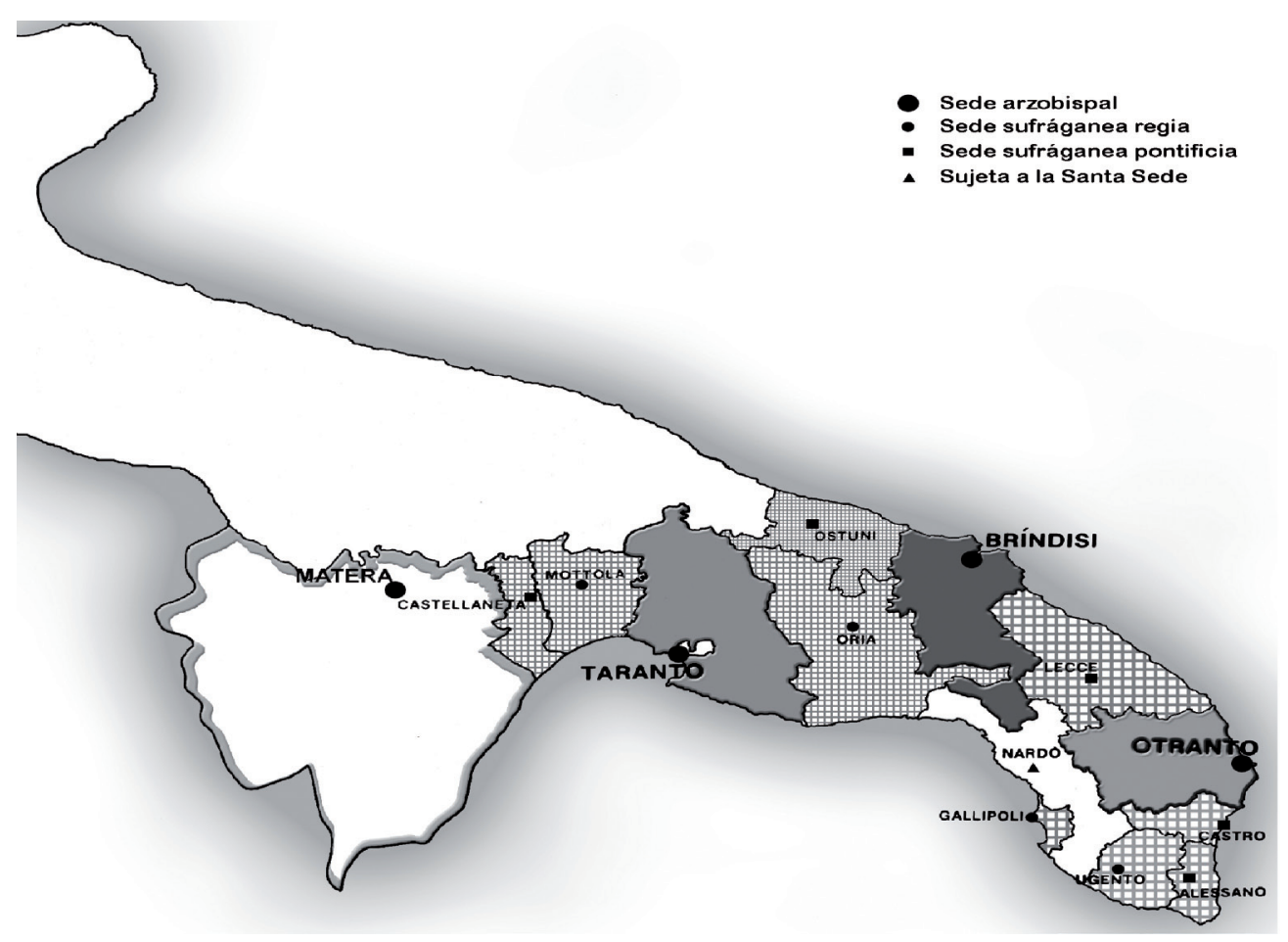

La geografía eclesiástica de Tierra d'Otranto:

la red organizativa diocesana anfíbia.

*Fuente: Paola Nestola, baseada en el mapa de DALL'AQUILA, C. (coord.): Cronotassi, iconografia e araldica dell'episcopato pugliese,

Regione Puglia, Assessorato alla Cultura, Bari, 1984, p. 65

ella también, y Ugento, localidad próxima a la costa. En el interior estaban las diócesis de Mottola y Oria. Esta última, a partir de 1591, fue de nombramiento real, después de la separación desde el único arzobispado "sin alternativa", es decir, Bríndisi. Según esta distribución espacial vemos configurarse una red eclesiástica cuyos ganglios lo constituían las metrópolis, de las que dependían las otras diócesis de la provincia. Dentro de este articulado sistema eclesiástico bajo el control del soberano, la ciudad de Otranto era la sede de mayor prestigio. Además de ser la más antigua, podía ostentar una cierta supremacía sobre las sufragáneas: un articulado universo de jurisdicción ciudadana, diocesana y provincial, documentado a fines del siglo XVI, concentrado en el arzobispo de Otranto que «reconocía a las causas de apelación de Lecce, Ugento, Gallipoli, Castro y Alessano, sufragáneos suyos, con obligación de obedecer al arzobispo en caso que él reuniese el sínodo diocesano ${ }^{33}$.

${ }^{33}$ Traducción del texto italiano por la que suscribe. ASNA, Cappellano maggiore, Processi di 
Una simbólica forma de preeminencia que se puso de manifiesto con ocasión del concilio diocesano y que - aunque no fuera muy evidente hasta mediados del siglo se añadía a otros privilegios ${ }^{34}$. Estos eran evidentes cuando el metropolitano asignaba muchos institutos eclesiásticos menores, como era el caso del nombramiento de los canónigos de la catedral y de otros beneficios de jus patronati en toda la diócesis o cuando gozaba de los títulos nobiliarios en algunos lugares y de los derechos de sucesión a los bienes de los que habitaban allí, muertos sin tener hijos ${ }^{35}$. Tal acervo de elementos materiales e inmateriales poseídos por el metropolitano de Otranto resalta aún más si se compara con el de las otras sedes arzobispales, tanto en aspectos jurisdiccionales cuanto patrimoniales. Una comparación que no siempre resultaba positiva para la antigua sede. Con respecto a la tarentina, la renta de la metrópoli adriática era de 3566 ducados frente a los casi 7339 ducados de la situada en el mar Jónico. La misma Bríndisi presentaba una situación mejor disponiendo de una renta de 4367 ducados. Desde el punto de vista de las diócesis dependientes Bríndisi, teniendo como sufragánea solo Ostuni, no podía competir con Otranto. Taranto a su vez aventajaba en tamaño a la sede adriática septentrional, un elemento de distinción más que se añadía al patrimonial. Dependientes suyas eran en efecto las sedes de Castelleneta, Mottola y Oria. Mientras en la primera, caracterizada por el hecho de ser una ciudad diócesis, era el papa quien decidía la selección, en las otras dos, a su vez, tras las modificaciones del privilegio carolino, se situaban obispos nativos del reino ${ }^{36}$.

Respecto a los estudios llevados a cabo hasta hoy, en estos últimos dos casos es necesario resaltar las "incertidumbres y contradicciones" que caracterizan la puesta en práctica del regio patronato. En concreto, en el caso de Mottola, habría que individualizar mejor los mecanismos de selección con los que venían elegidos sus obispos durante estos cuidadosos actos políticos. En efecto, en esta sede se ha podido individualizar algunos prelados que antes de instalarse en esta pequeña diócesis habían tenido importantes cargos en el "plantel" inquisitorial de la capital napolitana ${ }^{37}$. Aunque se tratase de una sede menor, podría tratarse de un temporal estacionamiento, un transitorio cargo hacia cursus honorum eclesiásticos más $\operatorname{ambiciosos}^{38}$.

\footnotetext{
Regio Patronato, vol. 1078, f. 177r-v.

${ }^{34}$ PALESE, op. cit. (nota 10) p. 86.

${ }^{35}$ ASNA, Cappellano maggiore, cit., f. 177r-v.

${ }^{36}$ SPEDICATO, op. cit. (nota 11, 1996), p. 14.

${ }^{37}$ Emblemáticos pueden ser los ejemplos del teatino Scipione Rebiba, y de Luigi Campagna. Sobre estos eclesiásticos: NESTOLA, op. cit. (nota 22) pp. 68, 61 y 72; sobre la organización de la red inquisitorial en el Reino de Nápoles: ROMEO, G.: L'Inquisizione a Napoli e nel Regno di Napoli nell'età di Filippo II: un bilancio, en LOTTI y VILLARI, op. cit. (nota 12), pp. 629-640.

${ }^{38}$ Por otros espacios de la monarquía católica: BARRIO GOZALO, M.: Burocracia inquisitorial y movilidad social. El Santo Officio, plantel de obispos (1556-1820), en PRADO MOURA, A. (ed.): Inquisición y sociedad, Valladolid, Universidad de Valladolid, 1999, pp. 107-138; PAIVA, J.P.: Origini e carriere vescovili nel Portogallo Moderno: una visione comparata, en Colòquio Internacional "A Igreja e o clero português no contexto europeu", Lisboa, Centro de Estudio de História Religiosa, Universidade Católica Portuguesa, 2005, pp. 277-291.
} 
El patrimonio de la diócesis de Mottola era a finales del siglo XVI de 1271 ducados, una renta que se obtenía del alquiler de parques y granjas, de censos y décimas ${ }^{39}$. Su titular gozaba de privilegios de nominación sobre un heterogéneo cuerpo de eclesiásticos: un grupo de coadjutores no muy compacto y que en muchos casos equivalía a un importante y básico trait d'union con las diversas actividades llevadas a cabo por la curia en el sector legislativo, judicial, administrativo, tanto como en el espiritual ${ }^{40}$. Liaisons importantes, sobre todo en los casos de prelados extraños a las dinámicas locales, y muy a menudo fieles colaboradores de una autoridad que con frecuencia no sabía moverse en los nuevos espacios sociales a los que había sido catapultada. En concreto, el obispo podía nombrar al vicario general de la ciudad, así como a los foráneos de otros lugares de la diócesis; también colacionaba los beneficios de la ciudad y de la entera demarcación cuando hacia la residencia ${ }^{41}$. Con respecto a otras, la sede de Mottola no era de las que contase con una elevada concentración de prelados de origen ibérico, como por ejemplo fueron los centros provinciales donde se aplicaba la alternativa, o eran destinados exclusivamente a extranjeros.

Aunque faltan nuevos estudios que analicen el conjunto de informaciones útiles para dibujar una prosopografía de este variado grupo social o que utilicen una perspectiva comparada con las otras áreas de la monarquía católica, entre el conjunto de eclesiásticos de origen hispánico que desarrollaron un poderoso cargo en el ámbito político-religioso, hay que destacar tres eclesiásticos casi desconocidos por la más reciente historiografía. Son prelados con un interesante currículo acumulado: se trata del arzobispo de Bríndisi fraile Dioniso O'Driscol, un franciscano nacido en Kinsale en 1600 y que desarrolló su papel pastoral por una larga temporada en esta área peninsular (1640-1650) ${ }^{42}$; del metropolitano de Otranto, el agustino Diego Lopes de Andrade (1623-1628) teólogo, predicador y autor de muchos tratados ${ }^{43}$; y el obispo de Ugento, el canonista Agustino Barbosa (marzo 1649-noviembre 1649) consultor de la Congregación romana del Índice y autor de fundamentales obras ${ }^{44}$. $\mathrm{Si}$ en el primer ejemplo se trata de un fiel representante irlandés, en los últimos dos casos se trata de nombramientos acaecidos en años cruciales para la unión de

\footnotetext{
${ }^{39}$ ASNA, Cappellano maggiore, cit., f. 183 r.

${ }^{40}$ En este aspecto faltan estudios específicos sobre la área ejemplificada: DONATI, C.: Curie, tribunali, cancellerie episcopali in Italia durante i secoli dell'età moderna: percorsi di ricerca, en NUBOLA, C. y TURCHINI, A. (eds.): Fonti ecclesiastiche per la storia sociale e religiosa d'Europa: XV-XVIII secolo, Bologna, Il Mulino, 1999, pp. 213-229; BRAMBILLA, E.: La polizia dei tribunali ecclesiastici e le riforme della giustizia penale, en ANTONIELLI L. y DONATI C. (eds.), Corpi armati e ordine pubblico in Italia (XVI-XIX sec.), Soveria Mannelli, Rubbettino, 2003, pp. 73-110.

${ }^{41}$ ASNA, Cappellano maggiore, cit. f., $184 \mathrm{v}$.

${ }^{42}$ GARCIA HERNÁN, E.: Obispos irlandeses y la Monarquía Hispánica en el siglo XVI, in Los extranjeros en la España moderna, Actas del I Coloquio Internacional, celebrado en Málaga del 28 30 de noviembre de 2002, GARCÍA, M.B. (dir.) vol. 2, 2003, pp. 275-280.

${ }^{43}$ Sobre el prelado portugués nacido en Lisboa en 1590 y muerto en Otranto en el 1628: BERNARD, P.: Andrade Diogo Lopes de, en Dictionnaire d'Histoire et de Geographie Ecclésiastiques, vol. II, 1914, Paris, Librairie Letouzey, p. 1590.

${ }^{44}$ Sobre este importante exponente del clero lusitano nacido en Guimarães en 1590 y muerto en Ugento en 1649: ALMEIDA (DE), F.: Barbosa Agostinho, en Dictionnaire d'Histoire et Geographie Ecclesiastiques, vol. VI, 1937, Paris, Librairie Letouzey, pp. 664-665.
} 
las coronas ibéricas (1580-1640) ${ }^{45}$. Son significativos ejemplos de plena inclusión en los mecanismos episcopales y de promoción social de lusitanos que se enmarcaron en una provincia virreinal donde activa era la presencia de portugueses, sobre todo en el campo económico-mercantil y feudal ${ }^{46}$. También, de estos eclesiásticos que llevaron sus tareas fundamentalmente fuera del país de origen, hay que analizar los mecanismos selectivos, así como la acción pastoral llevada en sus breves pero intensos mandatos.

Por otro lado las autoridades extranjeras ponían problemas lingüísticos-culturales con las poblaciones locales. Por eso los prelados necesitaban de personas seguras y, como en el caso de Otranto o de Mottola o de otras sedes donde el ordinario tenía derechos de nombramiento en las jerarquías menores, se creaban relaciones de tipo vertical. Interacciones creadas en tiempos específicos que establecían vínculos de confianza y de reciprocidad, en base a los cuales el patrono protegía a los hombres que le apoyaban y estos le aseguraban su lealtad.

Dinámicas elaboradas, estrategias calculadas al vértice del sistema que eran conocidas y criticadas, pero que hacían más farragoso el proceso de colación en el que participaban, en diferente grado, los diversos órganos de Nápoles, de Madrid y de Roma ${ }^{47}$. Un articulado calidoscopio de poderes, además de un sin número de personas que hacían hincapié al monarca y al Papa. Emblemático a todo punto de las peligrosas relaciones que se podían crear es un escrito anónimo de finales del siglo XVII que circulaba en el ambiente de la capital napolitana, en un periodo de fuertes contrastes entre la autoridad romana y la española sobre los asuntos inquisitoriales. Destacada la distinción entre el modelo de la acción del inquisidor y del obispo, en el escrito se subrayaba cómo los ordinarios eran premiados por méritos personales y servicios prestados al papado y a los príncipes; se ponía de manifiesto los corto circuitos que podían pasar por la fuerte dependencia entre el titular del pastoral y las personas inferiores del tribunal obispal como los vicarios ${ }^{48}$. Aunque con estas críticas, los engrasados engranajes de selección en los cuales se movían tantas personas, si por un lado individuaban y señalaban cuidadosamente al candidato, por el otro, premiaban a los súbditos fieles, garantizándose simultáneamente el control en las periferias.

${ }^{45}$ Para la presencia de lusitanos en la jerarquía obispal española: BARRIO GOZALO, M.: «La jerarquía eclesiástica en la España moderna. Sociología de una élite de poder (1556-1834)», Cuadernos de Historia Moderna, 25, (2000), pp.17-59, 34.

${ }^{46}$ VISCEGLIA, op. cit. (nota 4, 1988), p. 234; MUSI, A.: Mezzogiorno spagnolo. La via napoletana allo stato moderno, Napoli, Guida, 1991, p. 165; Sabatini G.: Los Vaaz en Nápoles en la edad de la Unión de Coronas: la trayectoria de una familia de banqueros portugueses entre asimilación y fracturas, Congreso Internacional "Integración y conflicto en la Monarquía de España durante el siglo XVII" (Valladolid, 23-24 ottobre 2008), en prensa.

${ }^{47}$ Véase el estudio comparativo sobre las dinámicas del proceso selectivo obispal en las distintas capitales de la Monarquia: PAIVA, op. cit., (nota 21) pp. 213-277, para la específica área del Reino de Nápoles, p. 223 y passim.

${ }^{48}$ Sobre este asunto me permito reenviar al documento encontrado en el Archivio de la Congregazione per la Dottrina della Fede (ex Santo Oficio de Roma) citado y comentado en NESTOLA, op. cit. (nota 24), pp. 249-250. 
Los acuerdos de 1529 focalizaron los intereses imperiales sobre específicos sitios de la provincia con evidente importancia simbólico-estratégica, pero no se detuvieron en los aspectos político-jurisdiccionales de la esfera eclesiástica, desde entonces adquiridos ab immemorabili o que se resentían de cíclicas coyunturas socioeconómicas. Junto a ello, un torbellino de factores físicos, sociales, económicos y políticos se integraba y se cruzaban. Concentrándonos en los centros seleccionados y reflexionando sobre los mecanismos de nómina, con la documentación en mano resultan evidentes otros aspectos de la complejidad de aquellas ambicionadas selecciones.

Como ya hemos indicado, las tres sedes portuarias de Tierra de Otranto eran ciudades de realengo, importantes centros urbanos directamente vinculados al soberano en los que vivían de forma permanente sus oficiales ${ }^{49}$. Cada una desempeñaba un importante papel en la dinámica jerarquía de los centros de la provincia, expuesta al enemigo que procedía del mar y obligada por tanto a hacerle frente a través de un sistema de centinelas y de tropas ${ }^{50}$. Al mismo tiempo esta área fronteriza estaba abierta a todo lo que llegaba de aquel fluido espacio: sea en términos materiales, es decir, mercancías y productos para cambiar y vender; sea como bienes inmateriales, noticias que circulaban de forma oral en los espacios sociales de los centros urbanos, o como informes escritos para las capitales del poder ${ }^{51}$.

Fue sobre todo durante el reinado de Felipe II cuando mejor se puede entender este conjunto de atenciones focalizadas en una parte del reino donde grande era el apremio por la obsesión turca. En efecto, es a partir de mediados del s. XVI, mientras la política eclesiástica gira en torno a la evolución del tratado carolino con el privilegio de la alternativa, cuando se fue mejorando el sistema defensivo constituido tanto por elementos fijos (castillos, torres costeras, murallas fortificadas) y móviles (como el servicio a caballo), puesto en funcionamiento para vigilar el territorio de las correrías marinas enemigas. Dentro del plan se encuadran también los proyectos de modernización de los castillos de Taranto, Bríndisi, Otranto,

\footnotetext{
${ }^{49}$ VISCEGLIA, op. cit. (nota 4, 1988), p. 199-219.

${ }^{50}$ HERNANDO SÁNCHEZ, C.: Castilla y Nápoles en el siglo XVI. El virrey Pedro de Toledo. Linaje, estado y cultura (1532-1553), Junta de Castilla y Leon, Valladolid, 1994, pp. 405-416; IDEM, El Reino de Nápoles. La fortificación de la ciudad y el territorio bajo Carlos V. IDEM (dir.): Las fortificaciones de Carlos V, Madrid, Ediciones del Umbral, 2000, pp. 513-553; COSI, G.: Torri marittime di Terra d'Otranto, Galatina, Congedo, 1989; FENICIA, G.: Il Regno di Napoli e la difesa del Mediterraneo nell'età di Filippo (1556-1598). Organizzazione e finanziamento, Bari, Cacucci, 2003.

${ }^{51}$ INFELISE, M.: Gli avvisi di Roma. Informazione e politica nel secolo XVII, en SIGNOROTTO, G.V. y VISCEGLIA, M.A. (eds.), La corte di Roma tra Cinque e Seicento "teatro" della politica europea, Bulzoni, Roma,1998, pp. 189-205; IDEM, Prima dei giornali. Alle origini della pubblica informazione, Laterza, Roma-Bari, 2002; IDEM, «Los orígenes de las gacetas. Sistemas y prácticas de la información entre los siglos XVI y XVII», Manuscrits, 23, (2005), pp. 31-44. Según un recorrido interdisciplinar dedicado al papel llevado por los extranjeros y forasteros en las ciudades: CALABI D. y TURK CHRISTENSEN S. (eds.): Cultural Exchange in Early Modern Europe, vol. II: Cities and Cultural Exchange in Europe, 1400-1700, Cambridge, Cambridge University Press, 2007; y BETHENCOURT F. y EGMOND F.(eds.) Correspondence and Cultural Exchange in Europe, 1400-1700, vol.III, en particular junto al artículo de M. Infelise, veáse además "Uses and Meanings of Correspondance: Noblemen, Peasants, Spies", ibidem, pp. 219-332.
} 
Gallipoli, Lecce, así como los de otros centros internos. A tan ambicioso proyecto costeado con financiación española, se añadió el plan de potenciación con Taranto y Bríndisi dispuesta a acoger un número mayor de navíos. La ciudad jónica quedaba peor resguardada debido a sus amplias bahías y sus abiertas costas de fina arena, que facilitaban el desembarco enemigo tanto como las peligrosas incursiones en el interior de la provincia. De modo distinto Bríndisi, contaba con un puerto grande y accesible, y poseía mejores condiciones logísticas y estratégicas para hacer más difícil la incursión enemiga ${ }^{52}$. Es interesante destacar la puntual relación hecha por el arzobispo frayle Andrés de Ayarde en julio 1592, casi después de un año desde su nombramiento ${ }^{53}$.

Potenciales presidios político-administrativos-militares, las ciudades sedes metropolitanas desempeñaban otras funciones estrechamente relacionadas con la necesidad de mantener vivo el vínculo de los territorios de frontera con los centros de decisión política. Otranto, por ejemplo, era uno de los nudos fundamentales en el sistema informativo sobre el Levante: desde la ciudad que daba el nombre a toda la provincia se enviaban al virrey de Nápoles y al rey hasta Madrid los informes de todo lo que ocurría en la otra orilla adriática y sus áreas internas ${ }^{54}$. A través del antiguo trazado de la vía Apia que finalizaba en Bríndisi y de la potenciación del servicio de correos arrendado a Juan de Zapata, el reino de Nápoles se comunicaba con el resto de Europa mediante la vía terrestre que unía España con las provincias meridionales italianas ${ }^{55}$. También Taranto estaba bien comunicada por tierra: cruzada por dos carreteras con importante función de enlace entre el Jónico y el Adriático. Esta demarcación oriental de la Tierra de Otranto tenía frecuentes contactos con las capitales del poder político y religioso, sirviéndose de un servicio de correos (procacci) semanales y mensajeros extraordinarios que la unían con Nápoles y Roma. Se viajaba pagando peajes, sobre caminos no exentos de peligros, de tal manera que la presencia de bosques llevaba a sus habitantes a lamentarse de la presencia de bandidos. Estos constituían un riesgo también para las autoridades, obstaculizando el secreto y la eficacia de las comunicaciones epistolares de naturaleza administrativa. Al punto que el arzobispo Lelio Brancaccio en 1595 llegó a publicar un edicto de excomunión a cuantos osasen abrir o falsificar los lacres oficiales. Cartas que podían contener noticias con graves consecuencias para los equilibrios locales e internacionales y que afectaban a personas o a comunidades enteras ${ }^{56}$.

${ }^{52}$ FENICIA, op. cit. (nota 50).

${ }^{53}$ AGS, Estado, 1093, c. 48.

${ }^{54}$ PRETO, P.: Il commercio: Venezia e Terra d'Otranto, en PELLEGRINO, B.: Storia di Lecce dagli Spagnoli all'Unità, Roma-Bari, Laterza, 1995, pp. 375-418; BETHENCOURT, F.: The political correspondence of Albunquerque and Cortés, en BETHENCOURT y EGMOND, op. cit. (nota 51), pp. 219-273; COUTO, D.: Spying in the Ottoman Empire: sixteen-century encrypted correspondence, ibidem, pp. 274-312.

${ }^{55}$ ASN, Collaterale, Curie, vol. 18, a. 1559, cc. 21v, 29 v, 199r. ; DE ROSA, L.: «Trasporti terrestri e marittimi nella storia dell'arretratezza meridionale», in Rassegna economica, 46, 3, (1982), pp. 682-705; OSTUNI, N.: Le comunicazioni stradali nel Settecento meridionale, Napoli, Edizioni Scientifiche Italiane, 1991.

${ }^{56}$ DE MARCO, V.: La diocesi di Taranto nell'età moderna (1560-1713), Roma, Edizioni di Storia 
Esta mezcla de aspectos socio-político-militares no deja de influir en el plano organizativo de la geografía eclesiástica de regio patronazgo y en cuanto se refiere a los distintos mecanismos de selección obispal según el derecho de la alternativa. Los documentos custodiados en el Archivo Histórico Nacional de Madrid desvelan los multiformes elementos evaluados en las complejas fases selectivas obispales, así como la tarea de las ciudades en las configuraciones de los equilibrios territoriales locales. Nuevos datos llaman a profundizar las interpretaciones ya asentadas por la historiografía que ha tratado la geografía eclesiástica de esta provincia, tenendo en cuenta no solamente los aspectos que pertenecían al peligro de ataques turcos. Esta obsesión era manifiesta por los menos hasta la gran empresa de Lepanto y por el consiguiente replanteamiento de la política mediterránea de la monarquía ${ }^{57}$. A pesar de todo ello, en los documentos aparecen referencias geopolíticas contemporáneamente a las alusiones a rentas y pensiones de la sede vacante y junto a opiniones sobre la calidad de los aspirantes, de sus redes clientelares y familiares a la que pertenecen. Una maraña de datos que hay de desentrañar para comprender plenamente los procesos y los intereses creados cuando había que decidir las nuevas plazas después de la muerte de un titular o cuando había que trasladar obispos de una sede a otra. En este contexto es interesante lo que sucedió en 1559 durante la elección del arzobispo de Otranto. Esta era una sede donde se aplicaba la alternativa, y en los documentos que se intercambiaban en el curso de la selección, se pone en evidencia la condición de ariete y de frontera que tenía la ciudad portuaria: «tanto más que estando Otranto al opposito de Valona y por esto tan sujetos los de allí a incussiones de cossarios y otros accidentes y rebatos de enemigos $\rangle^{58}$. Alejándonos hacia el Norte, siempre en el Adriático, en la circunscripción de Bríndisi, atribuida en cambio en exclusiva a obispos "españoles", en una consulta de 8 noviembre del 1650 a raíz de la muerte de su arzobispo de origen irlandés, fray Dionisio O'driscol, se hacía referencia explícita a la función estratégica militar de la ciudad, «aquella Iglesia cuya presentación toca a V.M. libre de alternativa de naturales por la calidad del puerto y castillo de mar y tierra de aquella ciudad $\aleph^{59}$. Algunos años más tarde, a las motivaciones de índole militar se añadían las de naturaleza política: «Brindiz puerto de mar y haver enel Presidio de españoles por lo qual siempre se provee en español $\aleph^{60}$. A su vez, la sede de Taranto, que sólo en época tardía la vemos ocupada por un forastero, presentaba una situación más articulada dada la importancia de su renta. Sobre esta sede estaban enfocadas las ambiciones tanto españolas como romanas. Sobre todo de esta última,

\footnotetext{
e Letteratura, 1988, p. 60; sobre el sistema de comunicaciones entre centro y periferias, entre obispos y Congregacion del Santo Oficio de Roma, me permito hacer referencia a un estudio mio y relativa bibliografia, I nervi del potere inquisitoriale: il sistema delle comunicazioni, en NESTOLA, op. cit. (nota 24) pp. 45-56.

${ }^{57}$ HERNANDO SÁNCHEZ, op. cit. (nota 50, 2000), p. 551.

${ }^{58}$ AHNM, Estado 2069, Sobre la provision del Arçobispado de Otranto y obispo del Aquila, 30 aprile 1579. 1650

${ }^{59}$ Ibidem, Sobre la yglesia de Brindez para consultar con su Magestad, consulta de 8 noviembre

${ }^{60}$ Ibidem, consulta de 15 de julio 1656.
} 
que escogía cardenales muchas veces residentes en Roma ${ }^{61}$. Así, al poco de la muerte de su titular, Lelio Brancacio, y en vista de la nueva designación, en una consulta de 5 de octubre de 1599, mientras de un lado se subrayaban los aspectos económicos y la falta de servicio originada por la ausencia de residencia de los prelados, del otro se resaltaban los requisitos que el nuevo candidato debería poseer:

«el Arçobispado de Taranto [...] por ser esta yglesia de las mas rica y qualificadas del Reyno de Napoles y la mayor de las que son a presentacion de V.M. y haven estado mucho años sin Prelado a causa de no haver residido enella los Arçobispos, se halla muy necesitada de quien atienda al buen govierno spirituale de aquellos subditos con mucho cuydado prudencia y buen zelo, y concurriendo estas y otras muy buenas partes y qualidades junto con muchas letras y doctrina $»^{62}$.

Después de largos años en el cargo del obispo de origen napolitano, que en los últimos años del mismo se había alejado de su demarcación, las propuestas hechas señalaban como favorito de la terna al benedictino Juan de Castro. Titular de un buen currículo y con una experiencia centrada en el servicio de la orden, el fraile tenía título de teólogo, siendo incluso buen predicador. El hecho que fuera hermano del Conde de Lemos constituyó -muy probablemente- uno de los principales factores de preferencia con respecto al de los dos candidatos que tenían más débiles apoyos, es decir, relaciones de servicio más que de parentesco ${ }^{63}$. El mandato del De Castro no duró mucho, debido a una muerte prematura de fecha aún incierta y en los mismos días de la acaecida al influyente virrey ${ }^{64}$. La circunstancia obligaba así de nuevo al órgano madrileño a iniciar consultas en 1602, que en base al principio de la alternativa debería concluirse con la elección de un prelado nacido en las provincias del Reino de Nápoles. Como ya fue señalado en la obra de Spedicato, el proceso quedó bloqueado debido al elevado número de concurrentes considerados protegidos, recayendo finalmente la nómina en 1605 en el napolitano Mirto Frangipane ${ }^{65}$.

Hasta ahora el análisis de esta heterogénea documentación había llevado a los investigadores a hacer hincapié en la candidatura a la mitra y en sus diferentes propuestas, en el tipo de protección que gravitaba en torno a los potenciales prelados interesados en hacerse cargo de la misma en función de su elevada renta, olvidándose de otros igualmente importantes que caracterizaban la diócesis. Una articulada jurisdicción con la que habría debido medirse la autoridad elegida.

Deteniéndonos en algunos elementos evidentes en la documentación, es posible identificar el interés con el que la administración española se tomaba el asunto,

\footnotetext{
${ }^{61}$ Sobre este aspecto ademas de DE MARCO, M. (op. cit.), DONATI, C.: Vescovi e diocesi d'Italia dall'età post-tridentina alla caduta dell'antico regime, en ROSA, M.: Clero e società nell'Italia moderna, Roma-Bari, Laterza 1992, pp. 321-389, 344-345.

${ }^{62}$ AHNM, Estado 2042, Consulta sobre la provision del Arçobispado de Taranto, 5 ottobre 1599.

${ }^{63}$ Ibidem.

${ }^{64}$ Sobre el articulado órgano de gobierno, véase un clásico de la historiografía: CONIGLIO, G.: I viceré spagnoli di Napoli, Napoli, Fiorentino, 1967.

${ }^{65}$ SPEDICATO, op. cit. (nota 11, 1996), pp. 86-87.
} 
preocupada en que no se alterara el precario equilibrio logrado tanto con la curia romana cuanto con la población del lugar. Así es posible delinear los primeros rasgos de un largo conflicto que enfrentará a la ciudad con Lelio Brancaccio, arzobispo de la misma entre 1574 y $1599^{66}$.

En las consultas, efectivamente, junto a las características económicas y político militares se insistía en su peculiaridad social que habría debido guiar todo el proceso. Sobre todo las negativas adjetivaciones asignadas al 'rebaño' constituían un motivo por el cual era necesario que la alternativa fuese respetada y preferido un prelado napolitano:

«siendo esta yglesia de las mas qualificadas del Reyno de Napoles, y la mas rica de las que son a presentacion de V.M. y en parte que conviene mucho a su real servicio que el prelado que la huviere de governar tenga valor y pecho para reprimir y componer con su exemplo y doctrina los excessos y differencias que suele haver por causa de bandas entre los subditos naturales de aquella ciudad que por la mayorparte es gente inquieta y bellicosa y por haver en ella castillo y presidios de Españoles muy importantes, ha parescido que non seria bien que se alterasse la alternativa tocando como toca esta vez la provision a natural del Reyno» ${ }^{67}$.

Igualmente, en 1627, con ocasión de una nueva selección en la que también estaba interesado el pontífice, se resaltaban los factores de naturaleza social, política, económica y militar que caracterizaban a la sede jónica. A treinta años de distancia del mandato de Lelio Brancacio, después de un episcopado en el que se habían instalado prelados procedentes del reino, en el contexto de las consideraciones del Consejo de Italia al soberano en torno a las ventajas y desventajas por las que aquella sede debía concederse a un candidato diferente a los presentados por el Papa, se esgrimía una batería de argumentos para no alterar el equilibrio ciudadano y de carácter político, económico y jurisdiccional conseguido en el campo de lo civil:

«seria de mucho inconveniente al govierno politico de la misma ciudad de Taranto que es de las mas principales del Reyno por poblacion y havitadores, delicias de mar y tierra y su sitio y puerto por la vesindad a los enemigos y ser como llave de aquella marinas [...]. Tiene V.M. un castillo de los mas importantes y el Virrey nombra cada año por V.M. un governador las mas vezes español, persona de muchas partes porlas ocurrencias que pueden succeder de su Real servicio y por que aquel Arçobispado es el de mayor rentas y estimacion del Reyno» ${ }^{68}$.

\footnotetext{
${ }^{66}$ Sobre este específico y contrastado obispado: DE MARCO, op. cit. (nota 56), pp. 49-119.

${ }^{67}$ AHNM, Estado 2042, consulta sobre la provision del Arçobispado de Taranto, 4 marzo 1602.

${ }^{68}$ Ibidem, consulta de 30 septiembre 1626, c.n.n..
} 
Tal concentración de poder en el espacio de la ciudad, tanto en aspectos materiales cuanto inmateriales de ámbito civil y eclesiástico, corría el riesgo de desequilibrarse en caso de que resultase elegido el candidato preferido por el Papa.

En el documento se evidenciaban, por tanto, otros aspectos relacionados con una práctica pastoral poco celosa, que sin respetar la residencia, hacia uso de otros colaboradores, devaluando todo un sistema de valores cultural - simbólicos, de privilegios, de derechos y jerarquías inculcado a través de rituales y ceremonias ${ }^{69}$. Un complejo universo que afectaba a toda la población, así como a las jerarquías civiles y religiosas de la ciudad, y al mismo tiempo un peligroso arsenal de guerra que la falta de residencia del titular favorecía. Un potente explosivo que, como en el caso que nos atañe, ponía en movimiento un candidato papal que además era de origen genovés:

«es mucho perjuicio al culto divino y servicio de Dios Nostro Senor que las Iglesias mayormente Arcobispales y metropolitanas como lo es esta de Taranto se confieran a cardenales que no las han de residir sino asistir en Roma para donde sacan todas las rentas que devian gastar en las mismas ciudades y diocesis e limosnas y otras obras de piedad y religion como dispone los sacros canones y concilios. Y sirviendo las Iglesias por vicarios o governadores no se tiene el decoro necessario al culto divino, disciplina ecclesiastica y reformacion de costumbres non solo de los seglares sino de los ecclesiasticos habriendose a unos y aotros con la ausencia de su prelado y pastor espiritual camino libre para vicios y soltura de vida con offensa a Dios, escandalo del publico y mal exemplo de los sufraganeos y convecinos occasionando tambien que se turbe la jurisdicion real de V.M. aun en las cosas mas asentadas y fundadas por derecho y costumbre immemorial del Reyno de Napoles ${ }^{70}$.

No de menor importancia eran los inconvenientes simbólicos - jurisdiccionales señalados, dificultades que se habrían manifestado con la elección de un candidato rival ratificado con un breve pontificio. Siempre que se condescendiera con la elección del pontífice, en efecto, se crearían precedentes que aplicar en casos semejantes, suprimiendo la posibilidad de premiar a candidatos españoles, a tal punto que el prelado seleccionado y premiado «no lo reconozeria de V.M. sino del papa atribuyéndolo a su intercesión lo cual podría obrar consecuencias prejudiciales ${ }^{71}$.

No es este el lugar para insistir sobre determinados aspectos - que sólo se pueden esbozar y en los que intentaremos profundizar - que forman parte de la "economía

\footnotetext{
${ }^{69}$ PAIVA, op. cit. (nota 28, 2002), pp. 415-425.

${ }^{70}$ AHNM, Estado 2042, consulta de 30 septiembre de 1626, c.n.n.

${ }^{71}$ Ibídem. Véase además cuanto se ponía de manifiesto en otro documento, donde se destacaban los problemas entre metropolita y sedes sufragáneas por la falta de residencia del arzobispo, Ibídem, consulta de 31 março 1627.
} 
de las mercedes" "72; remuneraciones muy criticadas por los publicistas de la época, incluso en los ambientes de la curia, en particular con lo relacionado con ciertas delicadas tareas del personal inquisitorial ${ }^{73}$.

En nuestro trabajo intentamos centrarnos en los parámetros sociales presentes en las consultas para la asignación del arzobispado de Taranto, indicadores que resaltan cómo a la ciudad se le reconocía la importancia de su factor demográfico. Tanto el documento de principios del siglo XVII como el de 1626 muestran la importancia dada por los órganos madrileños a la consistencia de la población, elemento que junto a las funciones eclesiásticas y administrativas connotaba las civitates del Reino de Nápoles ${ }^{74}$.

Dejando aparte el caso excepcional de Lecce, que en esos años detentaba un autentico primado demográfico ${ }^{75}$, en una mirada circunscrita en este aspecto demográfico de las tres ciudades meridionales de Tierra de Otranto, Taranto sobresale por el número de fuochi registrados: con respecto a los otros dos centros, Otranto y Bríndisi, la ciudad jónica era donde el número de familias fiscales era más alto. Según los datos demográficos - fiscales ofrecidos por María Antonietta Visceglia resulta evidente como frente a una situación en el centro tarentino de 3865 fuochi en 1561 (cifra que no encontraremos por debajo de 3000 hasta 1648) la ciudad de Otranto contaba apenas con 981(cifra que bajará en 1648 a 556), un valor muy inferior al de Bríndisi donde se registraban 1636 familias fiscales (que aumentará hasta 1946 en el posterior censo de mediados de siglos) ${ }^{76}$.

Citadas en los documentos españoles de consulta y confirmadas con los datos fiscales tanto a mediados del siglo XVI como del XVII, las elevadas cifras de Taranto hacían de esta ciudad el principal centro demográfico entre las archidiócesis. Sin embargo, su preeminencia demográfica no basta para explicar los adjetivos negativos con los que se definen a sus habitantes, según cuanto se refiere en 1602 durante el proceso de selección del obispo: «por la mayorparte es gente inquieta e bellicosa». Resaltando las peculiaridades politico-sociales de la ciudad, los órganos de gobierno españoles se mostraban particularmente sensibles a la necesidad de reforzar los lazos de dependencia, insertándose así en el complejo juego de equilibrios entre el respeto formal de los poderes locales y la acentuación del control central ${ }^{77}$.

\footnotetext{
${ }^{72}$ Sobre este articulado sistema: BARRIO, op. cit. (nota 21); PAIVA, op. cit. (nota 21).

${ }^{73}$ TABACCHI, S.: Nomine vescovili e ruolo del papa in un dibattito curiale di inizio Seicento, en OSSOLA, C. y otros (eds.): Religione cultura e politica nell'Europa dell'età moderna, Studi offerti a Mario Rosa dagli amici, Firenze, Olschki, 2003, pp. 263-275. Sobre las críticas en la colacion de obispados a prelados que hubieran tenido que desarrollar también el difícil cargo inquisitorial, NESTOLA, P.: Le penne dei grifoni: il caso di Terra d'Otranto, una regione di frontiera tra '500 e '600, en "A dieci anni dall'apertura dell'Archivio per la Congregazione della Dottrina della Fede, convegno di studi, Accademia dei Lincei, Roma, 21-23 febbraio 2008", en prensa.

${ }^{74}$ MUSI, A.: Storie "nazionali"e storie locali, en LERRA, A. (ed): Il libro e la piazza. Le storie locali nei Regni di Napoli e di Sicilia in età moderna, Manduria-Bari-Boma, Lacaita Editore, 2004, pp. 13-26.

${ }^{75}$ Sobre la evolución demográfica leccese: VISCEGLIA, op. cit. (nota 4, 1988), pp. 52-62.

${ }^{76}$ Ibidem, pp. 52-92.

${ }^{77}$ RAGGIO, O.: Visto dalla periferia. Formazioni politiche di antico regime e Stato moderno, en AYMARD, M.: (ed.), Storia d'Europa, vol. IV, L'età moderna, Torino, Einaudi, 1995, pp. 483-527.
} 
Tampoco es este un aspecto que en el estado actual de la investigación podamos delinear con claridad pero que intentaremos desarrollar centrando la atención en los súbditos, en los ciudadanos, entendidos como sujetos política y económicamente activos, capaces de responder y de enfrentarse a las propuestas del poder político central. Ciertamente un indicio, una traza útil quizás para entender plenamente lo sucedido en la segunda mitad del siglo XVI, tras el largo episcopado de Lelio Brancaccio, cuando se creó una peligrosa dinámica social que ostensiblemente enfrentaba la ciudadanía local al prelado, reiteradamente acusado a la curia y a la corona en memoriales y súplicas ${ }^{78}$. Durante sus 25 años de mandato, el aristocrático prelado napolitano titular de la populosa diócesis, tuvo que hacer frente a las numerosas acusaciones hechas por la multiforme ciudadanía, reacia a someterse al nuevo modus vivendi y a la desproporcionada acción disciplinaria puesta en práctica por el obispo - magistrado. Formado en Nápoles en un rígido clima contra-reformista, activo colaborador del sobrino de Paulo IV, Brancaccio fue elegido obispo de Sorrento, donde su mandato fue también muy impopular ${ }^{79}$. El nuevo nombramiento para Taranto se hizo según mecanismos que merecerán ser analizados en el futuro con un amplio abanico de opciones. De momento, hay que tener en consideración la anómala disponibilitad económica de esta autoridad 'anfibia' que se destacó como periférica centinela de la Congregación del Santo Oficio romano, solícito guadián de la ortodoxia frente a una situación virreinal que veía, sobre todo en este período, prelados muy pocos interesados a desarrollar un cargo tan peligroso y lleno de riesgos $^{80}$. Probablemente, este importante factor patrimonial permitió al obispoinquisidor llevar a cabo una amplia e incisiva acción de reforma: en sus contactos epistolares con la curia romana, el prelado formuló la intencion de construir nuevas cárceles: un medio para fortalecer la coercitiva acción legislativa y judicial ejercitada contra el 'rebaño' ciudadano y las poblaciones de griego-albaneses que poblaban su territorio jurisdiccional. Por otra parte, enmarcada en los cuadros provinciales de Tierra de Otranto, la infamante acción de excomulgar con público y violento castigo, si por un lado lo unía a cuanto hacía el prelado de la sede diocesana de Ostuni, Vincenzo Cornelio (1564-1578) ${ }^{81}$, por el otro, el intransigente celo le distinguía de la misericordiosa acción del ordinario de Lecce, Braccio Martelli, activo comisario itinerante del Santo Oficio de Roma ${ }^{82}$.

Son dinámicas heterogéneas, son lógicas pastorales distintas, que discurren entre mecanismos de inclusión y exclusión de los poderes obispales que hay que analizar,

\footnotetext{
${ }^{78}$ Agradezco al personal del AHNM por la localización del documento, AHNM, Estado 1409, c.n.n.

${ }^{79}$ Sobre este prelado: DE CARO, G.: Brancaccio Lelio, en Dizionario Biografico degli Italiani, vol. 13, Roma, Istituto Italiano Enciclopedia Italiana, 1971, pp. 785-787; BRAMBILLA, E.: Alle origini del Sant'Uffizio. Penitenza, confessione e giustizia spirituale dal medioevo al XVI secolo, Bologna, Il Mulino, 2000, pp. 531 y 533; MOTOLESE, G.: La Riforma Tridentina e la sua attuazione nell'archidiocesi di Taranto per opera dell'Arcivescovo Lelio Brancaccio (1576-1578), Manduria, Tiemme, 2002.

${ }^{80}$ ROMEO, op cit. (nota 37); NESTOLA, op. cit., (nota 22), p. 67.

${ }^{81}$ NESTOLA, op. cit., (nota 73).

${ }^{82}$ Eadem, op. cit., (nota 22), pp. 198-207.
} 
sin olvidar los reflejos que puedan tener en los mecanismos selectivos de corta y larga duracion. Aunque no podemos hacer un balance definitivo, de acuerdo con lo que muestran de forma indicativa los documentos de consulta, los memoriales de la numerosa y activa población de Taranto tuvieron algún éxito en los mecanismos de selección del importante arzobispado. Estos actos políticos fueron articulados según nuevas lógicas que tenían en cuenta un conjunto de aspectos jurisdiccionales, de poderes concurrentes en un sistema en el que el premio a la fidelidad ocupaba un relevante papel.

Las dinámicas periféricas activadas por las ciudades no siempre tuvieron las misma solución. Lecce, a su vez, alcanzada la condición de primer puesto político administrativo, no consiguió nunca la ambicionada primacía eclesiástica en la edad moderna. El diseño de alteración de los equilibrios eclesiásticos apoyado a nivel local por la autoridad eclesiástica y su entourage implicaba a la curia romana, pero también a la corona española dado el importante y coincidente interés político de la modificación en la región donde se había concentrado la hegemonía real. A mediados del siglo XVI, inestables eran todavía los equilibrios alcanzados con el tratado de Barcelona y flexible la aplicación del privilegio de la alternativa en la selección de los prelados para las sedes de designación real. Estos factores externos si de un lado favorecían la modificación de la malla eclesiástica del otro anunciaban otros intereses conflictivos que se centraban tanto en Lecce cuanto en la sede metropolitana. La nueva prestigiosa titulación querida por las oligarquías reforzaba sin duda el papel de la ciudad y de su obispo: sede del Tribunal de la real Audiencia, alcanzado el ansiado título habría conseguido una hegemonía de tipo jurídico - administrativo también en el campo eclesiástico. Si tal concentración y aumento de poder no eran bien vistos desde la curia romana, tanto menos la parte española se mostraba dispuesta a completarlo. En efecto, se incidía en la amplia jurisdicción que Otranto gozaba no sólo sobre Lecce sino también sobre las dependientes Gallipoli y Ugento (de nominación regia) e incluso sobre las sedes de nominación pontificia de Castro y Alessano. Como hemos visto, el titular metropolitano gozaba de numerosas prerrogativas sobre las sedes dependientes y ejercitaba funciones de control en las causas y temas llevados a los tribunales episcopales en materias religiosas y de costumbres.

Propuesto en un crucial momento de aproximación política por la monarquía española, empeñada en no perder los logros alcanzados en el tratado de 1529 y mejor definidos en el privilegio de la alternativa, frenado por la propia lentitud político burocrática de la sede apostólica, con papados de breve duración e implicada en esos mismos años en actuaciones políticas de gran envergadura ${ }^{83}$, el ambicioso juego a escala territorial se frenó definitivamente después de la muerte, en 1560, de Martelli. Ninguno de sus sucesores volvió a proponer el ambicioso proyecto que

${ }^{83}$ RIVERO RODRÍGUEZ, M.: La casa d'Austria e la Santa Sede nella congiuntura del 1550 e 1559: crisi dinastica e conflitti privati, en CANTÙ, F. y VISCEGLIA M.A.: L'Italia di Carlo V. Guerra, religione e politica nel primo Cinquecento, Atti del Convegno internazionale di Studi, Roma 5-7 aprile 2001, Roma, Viella, 2003, pp. 545-577; LUTZ, H.: Carlo V e il Concilio di Trento, en JEDIN, H. y PRODI, P.: Il concilio di Trento come crocevia della politica europea, Bologna, Il Mulino,1979, pp. 33-63, 55 y 57. 
parecía poder realizarse bajo el mandato de Felipe II y auspiciado por las grandes ambiciones de la autoridad eclesiástica ciudadana. Solo con el prelado napolitano Luigi Pappacoda (1639-1670) tuvo lugar una nueva reivindicación territorial de amplias consecuencias ${ }^{84}$. Una primacía regional alcanzada tras un largo paréntesis en el curso del cual la autoridad del obispo se había visto disminuida ante el papel hegemónico de las órdenes regulares existentes en la ciudad. Por tanto, teniendo que afirmar su autoridad en una ciudad en la que su papel había ido perdiendo importancia, Pappacoda centró su actuación en otros y nuevos factores/elementos de identidad ciudadana que simultáneamente relanzaban la importancia de su función e imponían un nuevo modelo de devoción y cultura a escala urbana y regional. En efecto, el obispo napolitano, tomando como modelo la figura del legendario, además de santo, obispo Oronzo de Lecce, consiguió elevarlo a la categoría de patrón de la ciudad, despertando las ambiciones de supremacía regional al adoptarlo como protector de Tierra de Otranto, salvada de la epidemia de peste de mediados del siglo XVII. Tan diferente y ejemplar supremacía, si de un lado señala el pasaje de la Lecce capital a la Lecce sagrada, del otro abre la devota difusión cultural a una gran parte de la provincia administrativa, extendiendo la hegemonía político cultural de Lecce más allá de los límites jurídicos de la metropolitana Otranto.

\section{Conclusión}

Los hilos del entramado que hemos presentados son todavía débiles en algunos puntos, pero son sin duda lo suficientemente consistentes como para tejer con ellos en un futuro investigaciones más precisas con las que (re)diseñar y colorear no sólo la compleja retícula espacial del territorio italiano sujeto a la monarquía hispánica sino también con los que (re)pensar las diferentes configuraciones a la que dio lugar la fragmentación de las sedes, siendo estas muy diferentes a tenor de su ubicación, consistencia demográfica y patrimonial, simbólico prestigio.

Los trazos de la geografía eclesiástica diocesana de investidura real en Tierra de Otranto se entrecruzan con las de designación papal, así como las circunscripciones administrativas de jurisdicción estatal, están divididas entre autoridades locales con idéntica legitimación pero intereses opuestos. Estas redes de relación y control puestas en marcha por los mecanismos de selección de obispos entre las elites extranjeras y locales, eran tejidas para reforzar la presencia de un poder político - jurisdiccional de compleja y difícil afirmación. El fragmentado territorio de colación real de la provincia suroriental del virreinato fue durante la edad moderna

${ }^{84}$ CAZZATO M., Tempore pestis: modi e morbi barocchi, en PELLEGRINO, B. y SPEDICATO, M.: Società, congiunture demografiche e religiosità in Terra d'Otranto nel XVII secolo, Galatina, Congedo, 1990, pp. 309-335; IDEM, La nascita di una città devota. Lecce al tempo del vescovo Pappacoda (1639-1670), en COSI, L. y SPEDICATO, M.: Vescovi e città nell'epoca barocca, vol. I. Murcia, Santiago de Compostela, Praga, Napoli, Catania, L'Aquila, Lecce, Galatina, Congedo 1995, pp. 151170; SPEDICATO, M.: La lupa sotto il pallio. Religione e politica a Lecce in Antico Regime, Laterza, Roma-Bari, 1996, pp. 79-90. 
reestructurado varias veces, tanto en la distribución de sus sedes cuanto en su organización. Su ordenación estaba en función del tamaño y de la renta diocesana pero también en función del papel asumido por la sede - a la vez activo centro urbano - y su territorio circundante. Íntimamente relacionados, tales aspectos resultaban especialmente evidentes en esta provincia donde se daba un heterogéneo sistema de circunscripciones eclesiásticas tanto en función de la extensión espacial - demográfica y de la cuantía de renta en cuanto a la función del prestigio. Una disparidad entre las sedes que resultaba palpable tanto a nivel horizontal que vertical de la organización. Tales aspectos simbólicos - materiales constituían elementos que diferenciaban circunscripciones del mismo nivel. Tanto el número de sedes sufragáneas cuanto el resto de privilegios de los que gozaba el titular de una provincia eclesiástica con respecto a los del titular de otra marcaban la diferencia. Elementos de prestigio como en el caso de la metropolia de Otranto, que resultaban aún más evidentes y profundos cuando se comparan los titulares de sedes diocesanas con los de las archidiócesis. Tal intríngulis de aspectos nos refleja la articulada trama creada entre el territorio, las funciones y los individuos. Osmótica madeja de hilos de diferente resistencia y color sobre los que es necesario insistir. Además de la articulada fragmentación que presenta el sistema diocesano, la figura del obispo adquiere un nuevo y espectacular perfil, esto es, el de una autoridad ordinaria asentada en ciertos lugares y formando parte del complejo plan estratégico político militar de la monarquía. Representante de una elite heterogénea, seleccionado por un poder estatal al que debe absoluta fidelidad y reconocimiento, legitimado a su vez por el papa, una autoridad que intenta a toda costa no perder jurisdicción. Caracterizado ya desde hace algunos años por la historiografía con inciertos contornos de autoridad anfibia, la figura del obispo del Ancient Règime se configura como un vivo agente social, que no debe traicionar los intereses privados y de la familia a la que pertenece, pero que debe afirmarse entre poderes locales, derechos, privilegios y costumbres. Teniendo presente los distintos planes de investigación y de escala todavía nos es posible leer el encabalgamiento de las instituciones, la madeja de jurisdicciones que limitaron o aumentaron el ejercicio de los poderes obispales en su forma inmaterial o material, de representación o de autoridad; de comprender la lógica de la acción pastoral, desarrollada entre estrategias de consenso y de relativa coerción como ejemplifica el obispo de Lecce Braccio Martelli, o de ejemplar e infamante castigo público como en el caso del arzobispo de Taranto Lelio Brancaccio. 